\title{
Endoscopic therapy of Barrett's: what more do we need to know?
}

\section{J-L Van Laethem, J Devière}

\section{Results emerging from endoscopic treatments to ablate Barrett's oesophagus indicate that APC alone or ALA-PDT in combination with APC achieves complete clearance of Barrett's epithelium in approximately two thirds of patients}

O ver the past few years, different endoscopic ablative techniques have been used in combination with antireflux therapy with the aim of reversing Barrett's oesophagus and replacing it with squamous epithelium. The end goal of these procedures is to impact directly on the risk of tumour development.

To date, most of the published results on ablative therapy in Barrett's oesophagus have dealt with a single treatment modality, and long term results as well as the real impact on the course of the condition remain unanswered.

The most widely used and studied procedures are photochemical (that is, photodynamic therapy (PDT) using Photofin or more recently 5-aminolevulinic acid (5-ALA) ${ }^{12}$ ) and thermal (that is, argon plasma coagulation (APC)). ${ }^{3}$

The study by Hage and colleagues, ${ }^{4}$ in this issue of Gut, is the first to compare two modalities [see page 785]. This was a well designed, prospective, randomised, three arm study involving 40 patients with non or low dysplastic Barrett's oesophagus, randomised to treatment with ALA-PDT as a single dose of $100 \mathrm{~J} / \mathrm{cm}^{2}(\mathrm{n}=13)$, ALA-PDT as a fractionated dose of 20 and $100 \mathrm{~J} / \mathrm{cm}^{2}$ $(\mathrm{n}=13)$, or APC $65 \mathrm{~W}$ for two sessions $(\mathrm{n}=14)$. All patients received omeprazole $40 \mathrm{mg}$ daily. After the designated treatment, any residual Barrett's oesophagus was treated with additional sessions of APC.

The end points of the study were endoscopic reduction of the Barrett's oesophagus surface and the microscopic presence or absence of intestinal metaplasia at different time points (that is, six weeks and 6, 12, 18, and 24 months). In the setting of endoscopic therapy of Barrett's oesophagus, complete histological ablation of specialised metaplastic epithelium should be considered the unique relevant end goal of these procedures as only complete histological clearance will influence the risk of cancer in this condition. Even in this scenario, only long term studies (more than five years) will tell us if this type of treatment is effective in preventing the need for surveillance and ultimately in reducing the risk of cancer development.

The results provided by the present randomised study are relatively similar to those reported in previous ones which assessed a single modality, particularly median length of Barrett's oesophagus $(3 \mathrm{~cm})$, proton pump inhibitor therapy, and duration of follow up (12 months) ${ }^{1-3}$

Clearly, there was no significant difference between the two procedures at six weeks, with a complete histological response rate of $33 \%$ and $36 \%$ for the ALA-PDT fractionated dose and APC, respectively. As additional treatment with APC was permitted in both groups for residual metaplastic mucosa, interpreting the 12 month results is difficult. However, it is interesting to note that residual Barrett's oesophagus was observed in only $10 \%$ of the ALA-PDT group and in $33 \%$ of the APC group, although the difference was not significant as the number of patients enrolled was relatively small.

The results from the ALA-PDT group compare favourably with previous reports: PDT is effective in eradicating high grade dysplasia or superficial tumours in $90-100 \%$ of cases but squamous re-epithelialisation was found in only two thirds of patients and was incomplete in all. ${ }^{25}$ The rate of residual Barrett's oesophagus after eradication using APC ranged from $0 \%$ to $68 \%$ in various series ${ }^{367}$ after a mean follow up period of approximately 12 months. It is not easy to explain this high variability which could depend on the technical procedure, length of the abnormal mucosa, and perhaps most importantly acid suppressive maintenance therapy.

In long term follow up studies (median follow up 36 months), we and others have clearly identified the length of the with regard to treatment procedures,
Barrett's segment and normalisation of acid exposure as the only independent predictive factors for sustained long term re-epithelialisation. ${ }^{78}$ However, other factors may be involved such as biliary reflux, or microenvironmental or genetic abnormalities. ${ }^{79} 10$

In summary, the study of Hage et al confirms results emerging from endoscopic treatments to ablate Barrett's oesophagus: APC alone or ALA-PDT in combination with APC achieves complete clearance of Barrett's epithelium in approximately two thirds of patients. The direct impact on the cancer risk in Barrett's oesophagus is unknown. Given the risk of developing adenocarcinoma arising under squamous re-epithelialisation, ${ }^{11} 12$ the potential complications of such endoscopic therapies, and the high cost of such management, we should follow the authors' recommendations of not using these techniques routinely. On the other hand, these modalities, especially PDT and its newer development in photosensitisation, offer fascinating perspectives for the curative management of early neoplastic changes and severe dysplasia arising in Barrett's oesophagus.

Finally, these experimental groups of patients, having already received treatment to eradicate Barrett's oesophagus, should be monitored in order to obtain valuable clinical information on the rate of tumour development over the next 10 years. All of these patients should be followed up with further endoscopic evaluations at five and 10 years.

Gut 2004;53:779-780.

doi: 10.1136/gut.2003.03639

\section{Authors' affiliations}

J-L Van Laethem, J Devière, Department of Gastroenterology, Erasme University Hospital, Brussels, Belgium

Correspondence to: Dr J-L Van Laethem, Department of Gastroenterology, Erasme University Hospital, 808 Route de Lennik, Brussels, Belgium; jvlaethe@ulb.ac.be

\section{REFERENCES}

1 Wang KK, Kim JY. Photodynamic therapy in Barrett's esophagus. Gastrointest Endosc Clin N Am 2003;13:483-9.

2 Gossner L, Stolte M, Sroka R, et al. Photodynamic ablation of high-grade dysplasia and early cancer in Barrett's oesophagus by means of 5 aminolevulinic acid. Gastroenterology 1998;114:448-55.

3 Franchimont D, Van Laethem JL, Devière J. Argon plasma coagulation in Barrett's oesophagus. Gastrintest Endosc Clin N Am 2003;13:457-66.

4 Hage M, Siersema PD, Van Dekken H, et al. 5Aminolevulinic acid photodynamic therapy versus argon plasma coagulation for ablation of Barrett's oesophagus: a randomised trial. Gut 2004;53:785-90

5 Overholt BF, Panjehpour M, Haydech JM. Photodynamic therapy for Barrett's esophagus. Follow-up in 100 patients. Gastrointest Endosc 1999;49:1-7. 
6 Schulz H, Miehlke S, Antos D, et al. Ablation of Barrett's epithelium by endoscopic argon plasma coagulation in combination with high-dose omeprazole. Gastrointest Endosc 2000;51:659-63.

7 Basu KK, Pick B, Bale R, et al. Efficacy and 1 year follow-up of argon plasma coagulation therapy for ablation of Barrett's oesophagus: factors determining persistence and recurrence of Barrett's epithelium. Gut 2002:51:776-80.
8 Kahaleh M, Van Laethem JL, Nagy N, et al. Longterm follow-up and factors predictive of recurrence in Barrett's esophagus treated by argon plasma coagulation and acid suppression. Endoscopy 2002;34:950-5.

9 Ouatu-Lascar R, Fitzgerald RC, Triadafilopoulos G Differentiation and proliferation in Barrett's esophagus and the effects of acid suppression. Gastroenterology 1999;117:327-35.

10 Krishmadath KK, Wang KK, Tomiguchi K, et al Persistent genetic abnormalities in Barrett's oesophagus after photodynamic therapy Gastroenterology 2000;1 19:624-30.

11 Van Laethem JL, Peny MO, Salmon I, et al. Intramucosal adenocarcinoma arising under squamous re-epithelialisation of Barrett's oesophagus. Gut 2000;46:575-7.

12 Shand A, Dallal H, Palmer K, et al. Adenocarcinoma arising in columnar lined Barrett's oesophagus following treatment with argon plasma coagulation. Gut $2001 ; 48: 580$

\section{Balancing the risks and benefits of infliximab in the treatment of inflammatory bowel disease}

\section{W J Sandborn, E V Loftus}

Patients with moderate to severely active Crohn's disease treated with infliximab may have a small but real risk of developing severe infections, opportunistic infections, and non-Hodgkin's lymphoma

ling fliximab, a monoclonal antibody to tumour necrosis factor (TNF) $\alpha$, is an important advance in the treatment of Crohn's disease. ${ }^{1-5}$ The efficacy of infliximab for the treatment of ulcerative colitis is still unclear. ${ }^{67}$ Infliximab was approved for the treatment of Crohn's disease in 1998 based on a 12 week phase 2 trial in 108 patients $^{1}$ (followed by a 36 week extension trial $)^{3}$ and a small phase 3 trial in 94 patients, ${ }^{2}$ both of which showed compelling efficacy. Because of the possibility of open label crossover at week 4, 102 of 108 patients in the phase 2 trial received infliximab by week 12 . Thus only six patients in the phase 2 study and 31 patients in the phase 3 study who received placebo were available for safety follow up without crossover to infliximab. Although not all patients enrolled in these studies were receiving concomitant corticosteroids and/or azathioprine or 6-mercaptopurine, regulatory approval in the USA was granted only in patients with moderate to severely active Crohn's disease unresponsive to conventional therapy (not defined) and for fistulising Crohn's disease; and in Europe in patients with moderate to severely active Crohn's disease or fistulising Crohn's disease unresponsive to a full and adequate course of corticosteroids and immunosuppressive therapy. These restrictions were, at least in part, a reflection of the uncertainties regarding safety.

Subsequently, two blinded, placebo controlled, phase 4 maintenance trials (designed as infliximab withdrawal trials) were conducted in 573 patients with moderate to severely active Crohn's disease $^{4}$ and in 306 patients with fistulising Crohn's disease. ${ }^{5}$ All patients in these two maintenance studies initially received at least one induction dose of infliximab. Thus safety data in patients with Crohn's disease treated only with placebo who were naïve to infliximab was available in only 34 of 1081 patients enrolled in placebo controlled trials. Potential treatment emergent safety issues in the other 1047 patients treated with infliximab in these clinical trials included non-Hodgkin's lymphoma in $2 / 1047(0.2 \%),{ }^{3}{ }^{4}$ opportunistic infections in $3 / 1047(0.3 \%)$ (tuberculosis $\mathrm{n}=1$; cytomegalovirus $\mathrm{n}=1$; cutaneous Nocardia $\mathrm{n}=1),{ }^{45}$ serious infections which occurred at rates of $4 \%$ and $4.6 \%$ in the two large maintenance trials, ${ }^{45}$ serum sickness-like reactions in $19 / 1047(1.8 \%),{ }^{4}{ }^{5}$ drug induced lupus in $2 / 1047(0.2 \%),{ }^{3}{ }^{4}$ and death in $4 / 1047$ $(0.4 \%)$ patients, including two deaths from lymphoma and a death from sepsis that were potentially related to inflix$\mathrm{imab}^{3-5}$ (one patient developed lymphoma during a maintenance trial and then died during follow $\mathrm{up}^{4}{ }^{8}$ ). Post- marketing safety reports or warnings from the US Food and Drug Administration have yielded additional information regarding the potential for opportunistic infections, including tuberculosis, ${ }^{9}$ disseminated histoplasmosis, ${ }^{10}$ coccidioidomycosis, listeriosis, and Pneumocystis carinii pneumonia, ${ }^{11}$ and possibly non-Hodgkin's lymphoma. ${ }^{12}$ Many of these post-marketing events occurred in patients with rheumatoid arthritis who have a median age 20 years older than that of patients with Crohn's disease.

In this issue of Gut, Ljung and colleagues $^{8}$ report on the clinical benefit and toxicity associated with the use of infliximab in a population based cohort of 217 patients with inflammatory bowel disease (Crohn's disease $\mathrm{n}=191$, ulcerative colitis $n=22$, indeterminate colitis $\mathrm{n}=4$ ) in Stockholm County, Sweden [see page 849]. Patients received a mean of 2.6 infusions of infliximab (range 1-11). Fifty four per cent of patients were also receiving azathioprine or 6-mercaptopurine, $51 \%$ were receiving corticosteroids, and 25\% were receiving both. The authors reported that the clinical benefit observed in patients with Crohn's disease was comparable with that reported in the controlled trials referenced above and in other uncontrolled reports of infliximab in clinical practice. ${ }^{13}$ The authors also reported that severe adverse events occurred in $41 \quad(18.9 \%)$ patients (Crohn's disease $n=35$, ulcerative colitis $\mathrm{n}=6$ ) including: non-Hodgkin's lymphomas in $3 / 217(1.4 \%)$ patients (Crohn's disease $\mathrm{n}=3$ ) of whom two died; severe infections in 18/217 (8.3\%) patients (Crohn's disease $n=11$, ulcerative colitis $\mathrm{n}=5)$; serum sickness-like reaction in 5/217 $(2.3 \%)$ (Crohn's disease $n=5)$; and drug induced lupus in $1 / 217(0.5 \%)$ (Crohn's disease $\mathrm{n}=1$ ). The severe infections included opportunistic infection in $2 / 217(0.9 \%)$ patients (listeriosis $\mathrm{n}=\mathrm{l}$ in a patient with Crohn's disease, Pneumocystis carinii $\mathrm{n}=\mathrm{l}$ in a patient with ulcerative colitis who died) and fatal sepsis in $2 / 217$ $(0.9 \%)$ patients (Crohn's disease $\mathrm{n}=1$, 
ulcerative colitis $n=1$ ). In total, $6 / 217$ $(2.8 \%)$ patients died in 28 months for a crude annual mortality of 1.2\%: 3/191 (1.6\%) patients with Crohn's disease died (non-Hodgkin's lymphoma $\mathrm{n}=2$, sepsis $n=1) ; 3 / 22(13.6 \%)$ patients with ulcerative colitis died (sepsis $\mathrm{n}=1$, Pneumocystis carinii $\mathrm{n}=1$, pulmonary embolus $\mathrm{n}=1$ ). All patients who died were receiving corticosteroids and most were elderly; at least two of the three patients who developed lymphoma were receiving or had previously received azathioprine.

Another study recently reported the safety experience in 500 consecutive patients with Crohn's disease treated with infliximab at the Mayo Clinic. ${ }^{14}$ Patients received a median of three infusions and had a median follow up of 17 months. Forty three patients $(8.6 \%)$ experienced a serious adverse event of which $30(6 \%)$ were considered to be possibly related to infliximab. Serum sickness-like disease occurred in $19 / 500$ patients and was attributed to infliximab in $14(2.8 \%)$. Three patients $(0.6 \%)$ developed drug induced lupus. One patient $(0.2 \%)$ developed a new demyelination disorder. Forty eight patients had an infectious event of which $41(8.2 \%)$ were attributed to infliximab. Twenty patients $(0.4 \%)$ had a serious infection: two fatal sepsis, eight pneumonias of which two were fatal, six viral infections, two abdominal abscesses requiring surgery, one arm cellulitis, and one histoplasmosis (opportunistic infection). Nine patients had a malignant disorder, three of which were possibly related to infliximab, including one lymphoma $(0.2 \%)$. A total of 10 deaths were observed over a median of 17 months, yielding a crude annual mortality of $1.3 \%$. For five of these patients $(1 \%)$, the events leading to death were possibly related to infliximab. Most of the patients who died were elderly.

These three data sets (controlled clinical trials, Ljung et al study, ${ }^{8}$ Colombel et al study ${ }^{14}$ ) show remarkable convergence for the frequency of the most important adverse events. Serious or severe infections occurred at a rate of $4.0-4.6 \%$ in clinical trials, $8.3 \%$ in the Ljung et al study, and $8.2 \%$ in the Colombel et al study. Opportunistic infection occurred at a rate of $0.3 \%$ in the clinical trials, $0.9 \%$ in the Ljung et al study, and $0.2 \%$ in the Colombel et al study. Serum sickness-like reactions occurred at a rate of $1.9 \%$ in the clinical trials, $2.3 \%$ in the Ljung et al study, and $2.8 \%$ in the Colombel et al study. Drug induced lupus occurred at a rate of $0.2 \%$ in the clinical trials, $0.5 \%$ in the Ljung et al study, and $0.6 \%$ in the Colombel et al study. Finally, death in patients with
Crohn's disease occurred at a crude annual rate of $0.4 \%$ in the clinical trials, $1.2 \%$ of patients in the Ljung et al study, and $1.3 \%$ of patients in the Colombel et al study. The mortality rate in these three data sets is comparable with what has previously been described in several studies of the natural history of Crohn's disease. ${ }^{15-17}$ Non-Hodgkin's lymphoma occurred at a rate of $0.2 \%$ in the clinical trials and in the Colombel et al study, and at a rate of $1.4 \%$ in the Ljung et al study. Based on these results from clinical trials, a referral centre, and a population based cohort, we can conclude that patients with moderate to severely active Crohn's disease treated with infliximab may have a small but real risk of developing severe infections, opportunistic infections, and nonHodgkin's lymphoma. However, it must be pointed out that all three data sets lack adequate controls, and one cannot be certain to what degree the potential bias of infliximab being given to the most refractory patients, and concomitant immunosuppressive therapy, may contribute to any possible risk.

Thus the important unanswered question is to what degree infliximab therapy caused or contributed to these serious adverse events and to the observed crude annual mortality rates? Population based studies in patients with Crohn's disease have shown only a slightly increased mortality ${ }^{15-22}$ (with three exceptions where no increased mortality was reported $)^{23-25}$ and no increased risk of non-Hodgkin's lymphoma ${ }^{26-29}$ (with one exception). ${ }^{30}$ However, these population based studies have not provided mortality or lymphoma rates adjusted for patient age, disease severity, or concomitant therapy with corticosteroids and/or azathioprine or 6-mercaptopurine. Clinical trials and observational studies have reported that corticosteroids ${ }^{31} 32$ and azathioprine ${ }^{33}$ may result in abdominal abscess, sepsis, and death; and that azathioprine and 6-mercaptopurine may be associated with non-Hodgkin's lymphoma. ${ }^{34-37}$ Thus the data reported in the clinical trials and by Ljung et al and Colombel et al must be interpreted with caution. At the present time all that we can really say is that patients with moderately to severely active Crohn's disease who are failing therapy with corticosteroids and/or immunosuppressive therapy and are subsequently selected for therapy with infliximab have a small but apparently real risk of serious infection, opportunistic infection, and possibly non-Hodgkin's lymphoma. It is unclear if the crude annual mortality rate is increased or not. Whether these adverse outcomes are directly caused by or exacerbated by infliximab, or are the result of other important confounders such as age, severity of illness, concomitant therapy with corticosteroids, concomitant therapy with azathioprine or 6-mercaptopurine, and combination therapy with corticosteroids and azathioprine or 6-mercaptopurine, is impossible to determine from the available data. Preliminary data from one large registry study in 5000 patients has reported that the severity of illness and corticosteroids account for virtually all of the infections and any excess mortality in patients with Crohn's disease treated with infliximab. ${ }^{38}$

To definitively address these issues, population based studies of patients treated with infliximab adjusted for important confounders are needed. Patient registries containing comparator patients not treated with infliximab will also be useful in this regard. Placebo controlled trials with infliximab (without crossover of placebo patients to infliximab) in patients with mild to moderately active Crohn's disease who are not receiving concomitant therapy with corticosteroids and/or immunosuppressives would also give a more clear signal regarding safety outcomes, but such studies may no longer be feasible. In general, clinicians should restrict the use of infliximab to patients with moderate to severely active Crohn's disease who have failed conventional therapy such as corticosteroids and immunosuppressive therapy with azathioprine, 6-mercaptopurine, or methotrexate. Patients with ulcerative colitis and indeterminate colitis should not be treated with infliximab until definitive evidence of efficacy from placebo controlled trials is available.

Gut 2004;53:780-782.

doi: $10.1136 /$ gut.2003.020552

\section{Authors' affiliations \\ W J Sandborn, E V Loftus, Inflammatory} Bowel Disease Clinic, Division of Gastroenterology and Hepatology, Mayo Clinic and Mayo Foundation, Rochester, Minnesota, USA

Correspondence to: Dr W J Sandborn, Mayo Clinic, 200 First Street SW, Rochester, MN 55905, USA; sandborn.william@mayo.edu

Conflict of interest. Dr Sandborn has received research support from, served as a consultant for, and participated in continuing medical education events sponsored indirectly by Centocor Inc.

\section{REFERENCES}

1 Targan SR, Hanauer SB, van Deventer SJ, et al. A short-term study of chimeric monoclonal antibody cA2 to tumor necrosis factor alpha for Crohn's disease. Crohn's Disease cA2 Study Group. N Engl J Med 1997;337:1029-35. 
2 Present DH, Rutgeerts P, Targan S, et al. Infliximab for the treatment of fistulas in patients with Crohn's disease. N Engl J Med 1999;340:1398-405

3 Rutgeerts P, D'Haens G, Targan S, et al. Efficacy and safety of retreatment with anti-tumor necrosis factor antibody (infliximab) to maintain remission in Crohn's disease. Gastroenterology 1999;117:761-9.

4 Hanaver SB, Feagan BG, Lichtenstein GR, et al. Maintenance infliximab for Crohn's disease: the ACCENT I randomised trial. Lancet 2002;359:1541-9.

5 Sands BE, Anderson FH, Bernstein CW, et al. Infliximab maintenance therapy for fistulizing Crohn's disease. N Engl J Med 2004; 350:876-85

6 Sands BE, Tremaine WJ, Sandborn WJ, et al. Infliximab in the treatment of severe, steroidrefractory ulcerative colitis: a pilot study. Inflamm Bowel Dis 2001:7:83-8.

7 Probert CS, Hearing SD, Schreiber S, et al. Infliximab in moderately severe glucocorticoid resistant ulcerative colitis: a randomised controlled trial Gut 2003·52:998-1002.

8 Liung $T$, Karlén $P$, Schmidt D, et al. Infliximab in inflammatory bowel disease: clinical outcome in a population based cohort from Stockholm County. Gut 2004;53.

9 Keane J, Gershon S, Wise RP, et al. Tuberculosis associated with infliximab, a tumor necrosis factor alpha-neutralizing agent. N Engl J Med 2001:345:1098-104.

10 Lee JH, Slifman NR, Gershon SK, et al. Lifethreatening histoplasmosis complicating immunotherapy with tumor necrosis factor alpha antagonists infliximab and etanercept. Arthritis Rheum 2002:46:2565-70.

11 Remicade (infliximab) for IV injection. Package Insert. Centocor, Malvern, Pennsylvania, USA, 2003.

12 Brown SL, Greene MH, Gershon SK, et al. Tumor necrosis factor antagonist therapy and lymphoma development: twenty-six cases reported to the Food and Drug Administration. Arthritis Rheum 2002;46:3151-8.

13 Ricart E, Panaccione R, Loftus EV, et al. Infliximab for Crohn's disease in clinical practice at the Mayo Clinic: the first 100 patients. Am J Gastroenterol 2001;96:722-9.

14 Colombel JF, Loftus EV jr, Tremaine WJ, et al. The safety profile of infliximab in patients with Crohn's disease: the Mayo Clinic experience in 500 patients. Gastroenterology 2004:126:19-31.

15 Jess T, Winther KV, Munkholm P, et al. Mortality and causes of death in Crohn's disease: follow-up of a population-based cohort in Copenhagen County, Denmark. Gastroenterology 2002;122:1808-14.

16 Loftus EV jr, Silverstein MD, Sandborn WJ, et al. Crohn's disease in Olmsted County, Minnesota, 1940-1993: incidence, prevalence, and survival. Gastroenterology 1998;114:1161-8.

17 Farmer RG, Whelan G, Fazio WW. Long-term follow-up of patients with Crohn's disease. Relationship between the clinical pattern and prognosis. Gastroenterology 1985;88:1818-25.

18 Palli D, Trallori G, Saieva C, et al. General and cancer specific mortality of a population based cohort of patients with inflammatory bowel disease: the Florence Study. Gut 1998:42:175-9.

19 Ekbom A, Helmick CG, Zack M et al. Survival and causes of death in patients with inflammatory bowel disease: a population-based study. Gastroenterology 1992;103:954-60.

20 Persson PG, Bernell O, Leijonmarck CE, et al. Survival and cause-specific mortality in inflammatory bowel disease: a population-based cohort study. Gastroenterology 1996; 1 10:1339-45

21 Loftus EV ir, Schoenfeld P, Sandborn WJ. The epidemiology and natural history of Crohn's disease in population-based patient cohorts from North America: a systematic review. Alimen Pharmacol Ther 2002;16:51-60.

22 Card T, Hubbard R, Logan RFA. Mortality in inflammatory bowel disease: a population based cohort study. Gastroenterology 2003; 125:1583-90

23 Farrokhyar F, Swarbrick ET, Grace RH, et al. Low mortality in ulcerative colitis and Crohn's disease in three regional centers in England. Am J Gastroenterol 2001;96:501-7.

24 Cottone M, Magliocco A, Rosselli M, et al. Mortality in patients with Crohn's disease. Scand J Gastroenterol 1996;31:372-5.

25 Probert CS, Jayanthi V, Wicks AC, et al. Mortality from Crohn's disease in Leicestershire, 1972 1989: an epidemiological community based study. Gut 1992;33:1226-8.

26 Lewis JD, Bilker WB, Brensinger C, et al Inflammatory bowel disease is not associated with an increased risk of lymphoma. Gastroenterology 2001;121:1080-7.
27 Ekbom A, Helmick C, Zack M, et al. Extracolonic malignancies in inflammatory bowel disease. Cancer 1991:67:2015-19.

28 Persson PG, Karlen P, Bernell O, et al. Crohn's disease and cancer: a population-based cohort study. Gastroenterology 1994:107:1675-9.

29 Loftus EV Jr, Tremaine WJ, Habermann TM, et al. Risk of lymphoma in inflammatory bowel disease. Am J Gastroenterol 2000;95:2308-12.

30 Bernstein CN, Blanchard JF, Kliewer $\mathrm{E}$, et al. Cancer risk in patients with inflammatory bowel disease: a population-based study. Cancer 2001;91:854-62.

31 Malchow H, Ewe K, Brandes JW, et al. European Cooperative Crohn's Disease Study (ECCDS): results of drug treatment. Gastroenterology 1984;86:249-66

32 Aberra FN, Lewis JD, Hass D, et al. Corticosteroids and immunomodulators: postoperative infectious complication risk in inflammatory bowel disease patients. Gastroenterology 2003;125:320-7.

33 Connell WR, Kamm MA, Ritchie JK, et al. Bone marrow toxicity caused by azathioprine in inflammatory bowel disease: 27 years of experience. Gut 1993;34:1081-5.

34 Present DH, Korelitz Bl, Wisch N, et al. Treatment of Crohn's disease with 6-mercaptopurine. A long-term, randomized, double-blind study. N Engl J Med 1980;302:981-7.

35 Bouhnik Y, Lemann M, Mary JY, et al. Long-term follow-up of patients with Crohn's disease treated with azathioprine or 6-mercaptopurine. Lancet 1996;347:215-19.

36 Dayharsh GA, Loftus EV jr, Sandborn WJ, et al. Epstein-Barr virus-positive lymphoma in patients with inflammatory bowel disease treated with azathioprine or 6-mercaptopurine. Gastroenterology 2002; 122:72-7.

37 Farrell RJ, Ang Y, Kileen $P$, et al. Increased incidence of non-Hodgkin's lymphoma in inflammatory bowel disease patients on immunosuppressive therapy but overall risk is low. Gut 2000:47:514-19.

38 Lichtenstein GR, Cohen RD, Feagan BG et al. Safety of infliximab in Crohn's disesse: data from the 5000-patient TREAT registry. Gastroenterology 2004; (abstract in press). know how to diagnose, treat, and even prevent this potentially fatal infection. ${ }^{34}$

Even the "spontaneous" nature of this infection has been largely resolved in recent years. We now know that the gut is the source of most of the bacteria that eventually cause SBP. ${ }^{5}$ As cirrhosis develops in animals, gram negative bacteria increase in numbers in the gut. ${ }^{5}$ We know that the gut of animals and patients with advanced cirrhosis is more permeable to bacteria than the normal gut and more permeable than the gut in less advanced cirrhosis. ${ }^{67}$ Once bacteria reach a critical concentration in the gut lumen, they "spill over", and escape the gut, "translocating" to mesenteric lymph nodes. Then they can enter lymph, blood, and eventually ascitic fluid. ${ }^{6}$ If the ability of the ascitic fluid to assist macrophages and neutrophils in killing the errant bacteria is deficient, uncontrolled growth occurs. ${ }^{8}$ This is SBP. In general, the animal or 
patient dies if they develop this infection and it is not promptly diagnosed and treated.

Thus SBP is the result of failure of the gut to contain bacteria and failure of the immune system to kill the virulent bacteria once they have escaped the gut. Patients and animals have duplicative mechanisms of protection from bacteria. This makes great sense teleologically. Opsonins assist motile and fixed "professional" killers of bacteria, the neutrophils and Kupffer cells, respectively. Innate defenders against bacterial invasion include macrophages, dendritic cells, and natural killer cells. These cells synthesise proinflammatory cytokines and effector molecules which assist in killing bacteria.

Unfortunately, patients with advanced cirrhosis have been reported to have defects and dysfunction in many of these systems of protection. ${ }^{8-11}$ It is then no surprise that these patients are vulnerable to infection by their own gut flora. To make matters worse, some of the effector molecules and cytokines that help kill the bacteria have undesired side effects. Nitric oxide (NO) is one of these effector molecules. Tumour necrosis factor (TNF) is one of the relevant cytokines. NO is probably the long sought after agent responsible for vasodilation that characterises advanced liver disease. ${ }^{12}$ Bacterial infection leads to further elevations in these molecules. ${ }^{13} 14$ NO and TNF are important mediators of the further vasodilation and renal failure that too often accompany SBP. ${ }^{14-16}$

The good news here is that selective intestinal decontamination with poorly absorbed antibiotics reduces gut bacterial counts, reduces translocation rates, can prevent SBP in high risk subgroups, and can improve the hyperdynamic circulatory state of these patients. ${ }^{3}{ }^{17} 18$ Selective intestinal decontamination can even improve survival of rats with cirrhosis and ascites. ${ }^{19}$

This brings us to the most recent contribution to this line of investigation published by Francés and colleagues ${ }^{20}$ in this issue of Gut [see page 860]. These investigators have previously shown that some patients with cirrhosis have bacterial DNA in their serum and ascitic fluid, and that the DNA is always present simultaneously in both body fluids. ${ }^{21}$ This provides molecular evidence of bacterial translocation. They have also shown that patients who subsequently develop SBP have a higher baseline ascitic fluid TNF level than patients who do not develop SBP. ${ }^{22}$ It is probable that in patients and in rats with cirrhosis that SBP is preceded by episodes of colonisation of blood and ascitic fluid with viable bacteria or translocated pieces of bacteria (for example, DNA). ${ }^{23}{ }^{24}$ Bacterial DNA can bind to the toll-like receptor 9 of cells of the innate immune system and activate them. ${ }^{25}$ Host immune defences are able to kill the bacteria in these episodes of colonisation that do not progress to SBP. SBP occurs (a) when the organism is more virulent than the bacteria that were killed by host immune defences at the stage of colonisation, (b) when immune defences weaken, or (c) a combination of these events. It is the peritoneal macrophage that is the first line of defence against bacterial colonisation of ascitic fluid. ${ }^{26}$ SBP occurs when macrophages fail to kill the bacteria and the second line of defence is called in, the neutrophils.

Based on the information presented above, one would predict that the presence of whole bacteria or DNA in serum and ascitic fluid would have consequences (for example, stimulation of immune defences, effector molecules, and cytokines). This could in turn impact on haemodynamics, renal function, and survival. These effector molecules and cytokines are two edged swords. They can protect from bacterial infection but they can also initiate a sequence of events than can lead to the patient's death.

The elegant study in this issue furthers this line of investigation and provides the scientific rationale for new clinical studies, including a randomised controlled trial..$^{20}$ The authors harvested peritoneal macrophages from patients with cirrhosis and ascites. Approximately one third of their patients had detectable bacterial DNA. They divided the patients into two groups: those with and without bacterial DNA in serum and ascitic fluid. They measured macrophage production of NO metabolites and cytokines, including TNF, and compared the results between the two groups. The authors convincingly demonstrate that peritoneal macrophages from patients with cirrhosis and bacterial DNA in serum and ascitic fluid are markedly activated, as evidenced by increased NO synthesising ability and enhanced cytokine production. ${ }^{20}$ This study provides further insight into very early events in the pathogenesis of SBP. Pieces of bacteria commonly escape the gut and end up in blood and ascitic fluid. In the process, a complex sequence of events occurs. The immune system is stimulated to contain the bacterial colonisation and protect the host from fatal infection. However, as a consequence, the effector molecules and cytokines are increased, setting the stage for worsening of the haemodynamic status, development of functional renal failure, and the possibility of death.
Now that this new subset of patients with molecular evidence of translocation has been identified, it is perhaps time to perform a prospective study following those patients who are positive for bacterial DNA and determining if their risks of SBP, hepatorenal syndrome, and death are higher than those of DNA negative controls. If excessive morbidity and/or mortality are documented, the next step would be to conduct a randomised controlled trial of selective intestinal decontamination versus placebo in the DNA positive group and determine if hepatorenal syndrome and death can be prevented.

Gut 2004;63:782-784.

doi: 10.1136/gut.2003.035311

Correspondence to: Professor B A Runyon, Chief, Liver Service, Loma Linda University Medical Center, 11234 Anderson Street, Room 1556, Loma Linda, California, 92354, USA; Brunyon@ahs.llumc.edu

\section{REFERENCES}

1 Conn HO, Fessel JM. Spontaneous bacterial peritonitis in cirrhosis: variations on a theme. Medicine 1971:50:161-97.

2 Pinzello G, Simonetti RG, Craxi A, et al. Spontaneous bacterial peritonitis: a prospective investigation in predominantly nonalcoholic cirrhotic patients. Hepatology 1993:3:545-9.

3 Rimola A, Garcia-Tsao G, Navasa M, et al. Diagnosis, treatment and prophylaxis of spontaneous bacterial peritonitis: a consensus document. J Hepatol 2000;32:142-53.

4 Runyon BA. Management of adult patients with ascites caused by cirrhosis. Hepatology 1998;27:264-72.

5 Guarner C, Runyon BA, Young S, et al. Intestinal bacterial overgrowth and bacterial translocation in an experimental model of cirrhosis in rats. $J$ Hepatol 1997;26:1372-8.

6 Runyon BA, Squier SU, Borzio M. Translocation of gut bacteria in rats with cirrhosis to mesenteric lymph nodes partially explains the pathogenesis of spontaneous bacterial peritonitis. J Hepatol 1994;21:792-6.

7 Cirera I, Baver TM, Navasa M et al. Bacterial translocation of enteric organisms in patients with cirrhosis. J Hepatol 2001;34:32-7.

8 Runyon BA. Patients with deficient ascitic fluid opsonic activity are predisposed to spontaneous bacterial peritonitis. Hepatology 1988;8:632-5.

9 Runyon BA, Morrissey R, Hoefs JC, et al. Opsonic activity of ascitic fluid: a potentially important protective mechanism against spontaneous bacterial peritonitis. Hepatology 1985;5:634-7.

10 Fiuza C, Salcedo M, Clemente G, et al. In vivo neutrophil dysfunction in cirrhotic patients with advanced liver disease. J Infect Dis 2000;182:526-33.

11 Rimola A, Soto R, Bory F, et al. Reticuloendothelial system phagocytic activity in cirrhosis and its relation to bacterial infections and prognosis. Hepatology 1984;4:53-8.

12 Wiest R, Groszmann RJ. The paradox of nitric oxide in cirrhosis and portal hypertension: too much, not enough. Hepatology 2002; 35:478-91.

13 Jimenez W, Ros J, Morales-Ruiz M, et al. Nitric oxide production and inducible nitric oxide synthase expression in peritoneal macrophages of cirrhotic patients. Hepatology 1999;30:670-6.

14 Such J, Hillebrand DJ, Guarner C, et al. Nitric oxide in ascitic fluid is an independent predictor of renal impairment in patients with cirrhosis and spontaneous bacterial peritonitis. Eur J Gastroenterol Hepatol, 2004 (in press).

15 Follo A, Llovet JM, Navasa M, et al. Renal impairment after spontaneous bacterial peritonitis in cirrhosis: incidence, clinical course, predictive 
factors and prognosis. Hepatology 1994:20:1495-501.

16 Ruiz-del-Arbol L, Urman J, Fernandez J, et al. Systemic, renal, and hepatic hemodynamic derangement in cirrhotic patients with spontaneous bacterial peritonitis. Hepatology 2003;38:1210-18.

17 Runyon BA, Borzio M, Young S, et al. Effect of selective intestinal decontamination with norfloxacin on spontaneous bacterial peritonitis, translocation, and survival in an animal model of cirrhosis. Hepatology 1995;21:1719-24.

18 Rasaratnum B, Kaye D, Jennings G, et al. The effect of selective intestinal decontamination on the hyperdynamic circulatory state in cirrhosis. Ann Intern Med 2003;139:186-93.
19 Guarner C, Runyon BA, Heck M, et al. Effect of long-term trimethoprim/sulfamethoxazole prophylaxis on ascites formation, bacterial translocation, spontaneous bacterial peritonitis and survival in cirrhotic rats. Dig Dis Sci 1999:44:1957-62.

20 Francés R, Muñoz C, Zapater $P$, et al. Bacteria DNA activates cell mediated immune response and nitric oxide overproduction in peritoneal macrophages from patients with cirrhosis and ascites. Gut 2004;53:860-4.

21 Such J, Francés R, Muñoz C, et al. Detection and identification of bacterial DNA in patients with cirrhosis and culture-negative, nonneutrocytic ascites. Hepatology 2002;36:135-41.

22 Such J, Hillebrand DJ, Guarner C, et al. Tumor necrosis factor-alpha, interleukin- 6 and nitric oxide in sterile ascitic fluid and serum from patients who subsequently develop ascitic fluid infection. Dig Dis Sci 2001;46:2360-6.

23 Runyon BA. Monomicrobial nonneutrocytic bacterascites: a variant of spontaneous bacterial peritonitis. Hepatology 1990;12:710-15.

24 Runyon BA, Sugano S, Kanel G, et al. A rodent model of cirrhosis, ascites, and bacterial peritonitis. Gastroenterology 1991;100:489-93.

25 Wagner $\mathbf{H}$. Interactions between bacterial CpGDNA and TLR9 bridge innate and adaptive immunity. Curr Opin Microbiol 2002:5:62-9.

26 Dunn DL, Barke RA, Knight NB, et al. Role of resident macrophages, peripheral neutrophils and translymphatic absorption in bacteria clearance from the peritoneal cavity. Infect Immun 1985:49:257-64. 